\title{
Can clinical prediction tools predict the need for computed tomography in blunt abdominal? A systematic review
}

Alistair Sharples (Corresponding author)

Affiliations: 1: University Hospital of North Midlands

2: $\quad$ Queen Mary University of London and Barts and The London School of Medicine and Dentistry, London, UK

E-mail: alsharples@yahoo.co.uk

Telephone: +447590469569

Home address: 8 Alexandra Street, Stone, ST15 8HL.

Institutional address: Centre for Trauma Sciences, Blizard Institute, Queen Mary University of London, London, UK.

Other authors:

\section{Karim Brohi}

Affiliations: 1: Queen Mary University of London and Barts and The London School of Medicine and Dentistry, London, UK 


\section{Can clinical prediction tools predict the need for computed tomography in blunt abdominal trauma? A systematic review}

Keywords: Blunt abdominal trauma, clinical prediction tools, computed tomography. 


\begin{abstract}
Introduction

Blunt abdominal trauma is a common reason for admission to the Emergency Department. Early detection of injuries is an important goal but is often not straightforward as physical examination alone is not a good predictor of serious injury. Computed tomography (CT) has become the primary method for assessing the stable trauma patient. It has high sensitivity and specificity but there remains concern regarding the long term consequences of high doses of radiation. Therefore an accurate and reliable method of assessing which patients are at higher risk of injury and hence require a CT would be clinically useful. We perform a systematic review to investigate the use of clinical prediction tools (CPTs) for the identification of abdominal injuries in patients suffering blunt trauma.
\end{abstract}

\title{
Materials and Methods
}

A literature search was performed using Medline, Embase, The Cochrane Library and NHS Evidence up to August 2014. English language, prospective and retrospective studies were included if they derived, validated or assessed a CPT, aimed at identifying intra-abdominal injuries or the need for intervention to treat an intraabdominal after blunt trauma. Methodological quality was assessed using a 14 point scale. Performance was assessed predominantly by sensitivity.

\section{Results}

Seven relevant studies were identified. All studies were derivative studies and no CPT was validated in a separate study. There were large differences in the study design, composition of the CPTs, the outcomes analysed and the methodological quality of the included studies. Sensitivities ranged from $86-100 \%$. The highest performing CPT had a lower limit of the $95 \% \mathrm{Cl}$ of $95.8 \%$ and was of high methodological quality (11 of 14). Had this rule been applied to the population then $25.1 \%$ of patients would have avoided a CT scan.

\section{Conclusions}

Seven CPTs were identified of varying designs and methodological quality. All demonstrate relatively high sensitivity with some achieving very high sensitivity whilst still managing to reduce the number of CTs performed by a significant amount. Further studies are required to validate the results obtained by the highest performing CPTs before any firm recommendation can be used regarding their use in routine clinical practice. 


\section{Introduction}

Blunt abdominal injury (BAT) is common and is associated with intra-abdominal injury (IAI) in $8-17 \%^{1-4}$. Early detection of these life threatening injuries is critically important. Physical examination alone is not a good predictor of $\mid \mathrm{Al}^{5-8}$. Significant, life threatening injuries can be present in the absence of obvious clinical signs ${ }^{2,8}$. This is especially true in the presence of a head injury or other distracting injuries ${ }^{7,9}$.

Computed tomography (CT) has become the primary method for investigating the stable trauma patient. The sensitivity and specificity of CT for identifying IAI is high at 96-100\% and $94-100 \%$ respectively ${ }^{10-14}$ and it has a very low rate of missed injuries ${ }^{12}$. However, the pick-up rate from such scans if often very low ${ }^{15}$. One study suggested that as few as $1 \%$ of haemodynamically stable patients with BAT have significant $|A|^{16}$. Other studies have suggested that stable BAT patients without clinical evidence of IAI can be safely managed without $\mathrm{CT}^{17-19}$.

Increasingly whole-body CT (WBCT) is being used as a form of triage $\mathrm{e}^{20-22}$. Supporters have argued that WBCT enables more rapid diagnosis and therefore earlier treatment and that it leads to fewer missed injuries ${ }^{23-27}$. Opponents will argue that it can delay intervention, is more expensive and exposes patients to higher radiation doses $^{28-29}$.

A number of studies have attempted to demonstrate a benefit to unselected WBCT ${ }^{30-40}$. Most of these studies agree that unselected WBCT reduces time to diagnosis, time to surgery and time spent in the Emergency Department ${ }^{30-32,35,41}$. Its use has been shown to reduce mortality in patients with impaired consciousness and haemodynamic instability ${ }^{33,36}$. Of course, demonstrating the utility of WBCT in high risk patients (such as those with impaired consciousness and haemodynamic instability) is not the same as proving it is appropriate for patients without obvious signs of injury. Gupta et al found there was a very low incidence of clinically relevant abnormalities when WBCT was performed in the absence of a specific clinical indication $^{38}$.

Only one study has specifically studied the use of routine WBCT in haemodynamically stable patients with no signs or symptoms of injury ${ }^{37}$. It claimed that $7.1 \%$ of abdominal CT scans showed clinically significant findings. However, most of these injuries were relatively minor and it is unknown how many of these injuries may have been suggested by physical examination or bedside diagnostic studies.

Increasingly, concerns have been raised about the risks posed by excessive use of CT. lonising radiation is a known carcinogen and is associated with a number of malignancies ${ }^{42,43}$. Much of the evidence behind this comes from non-medical radiation exposures ${ }^{44-46}$, but there is evidence to suggest that exposure to doses of $10-100 \mathrm{mSv}$ (the range more relevant to medical imaging) can increase the risks of malignancy ${ }^{47}$. Compared with conventional radiography, CT exposes patients to 
significantly higher radiation doses and these doses have been shown to increase substantially when liberal trauma CT policies are implemented ${ }^{48}$.

Lifetime risks vary from 1 in 1250 in a 45 year old patient undergoing a whole body CT to 1 in 250 for a 20 year old woman undergoing an abdominal $\mathrm{CT}^{49,50}$. The risks are significantly higher in paediatric patients and young adults due to their increased susceptibility to radiation ${ }^{51-53}$.

A clinical prediction tool (CPT) is a tool designed to guide clinicians in making management decisions ${ }^{54}$. They combine multiple independent variables to create a score which can be useful in establishing a diagnosis or in deciding on further investigations or treatment options ${ }^{55}$. They are commonly used for determining the need for head and cervical spine imaging after trauma ${ }^{56-60}$.

This study aims to perform a systematic review of the literature looking at the use of CPTs aimed at identifying lower risk blunt trauma patients who can be managed without the need for a CT scan of the abdomen. We aim to identify and evaluate the methodological quality and the clinical performance of existing CPTs used in adults with BAT. 


\section{Methods}

A systematic review and meta-analysis was performed. This was performed using the Preferred Reporting Items for Systematic Reviews and Meta-Analysis (PRISMA) recommendations ${ }^{61}$.

English language, prospective and retrospective studies were included if they derived, validated or assessed a CPT aimed at identifying IAI (all injuries or clinically relevant injuries only), or the need for intervention to treat an IAI after BAT. For the purposes of this study, a CPT was defined as: a tool which includes three of more variables and where the presence of any one of these variables renders the CPT positive. The variables may be obtained from the history, physical examination or from simple diagnostic tests available at the bedside in the Emergency Department (arterial or venous blood analysis, urinalysis, plain x-rays or focussed assessment with sonography in trauma (FAST) scan).

Studies were excluded if they: assessed the predictive value of individual variables only; assessed the predictive value of variables without the intention of creating a CPT; included only patients under the age of 18; or included patients with penetrating trauma.

A literature search was performed using Medline, Embase, The Cochrane Library and NHS Evidence up to August 2014. The search was performed using combinations of keywords such as: clinical prediction tools; computed tomography; CT scan; blunt abdominal trauma; blunt abdominal injury; intra-abdominal injury (see Appendix 1 for full search strategy). In addition to the above databases, studies published in four core journals (Annals of Surgery, European Journal of Trauma and Emergency Surgery, British Journal of Surgery and Journal of Trauma and Acute Care Surgery [previously known as the Journal of Trauma, Injury, Infection and Critical Care]) since January 2004 were hand searched. The reference lists of included studies were also searched manually for additional studies.

Studies identified by the search strategy above were screened for inclusion using a two-step process. Firstly, the titles and abstracts of each study were assessed. Secondly, the full text was assessed for studies which were thought to be potentially relevant and studies where relevance remained uncertain.

Data collected included: details on study design; the inclusion and exclusion criteria used in each study; the indications for performing a CT scan; the predictor variables included in the CPT; the outcome measures used; sensitivity, specificity, positive (PPV) and negative predictive values (NPV) and the proportion of patients who would have received a CT had the CPT been implemented.

The included studies were assessed using a 14 point scale adapted from published guidelines used for the derivation of CPTs ${ }^{62-66}$. The 14 questions asked of each paper can be seen in Table 2 (for more details see Appendix 2). For each item a mark of 0 was awarded if the criteria was not fulfilled (or if it could not be ascertained from the 
paper whether the criteria was fulfilled) and a mark of 1 awarded if it was fulfilled. The maximum total score was therefore 14.

CPTs assessing the presence of an injury were assessed separately to those assessing the need for acute intervention. For the purposes of determining the most effective CPT it is assumed that sensitivity is considered the most important single measure.

Stats Direct version 3.0.141 (StatsDirect Ltd., Altrincham, UK)) was used to analyse data. Sensitivity, specificity, PPV and NPV were expressed as a percentage with $95 \%$ confidence intervals. Individual predictors were expressed as odds ratios with $95 \%$ confidence intervals. Pooled odds ratios were calculated using the Dersimonian-Laird random effects mode ${ }^{67}$. A p-value of less than 0.05 was considered statistically significant. Heterogeneity was expressed using $\mathrm{I}^{2}$, where values of $25 \%, 50 \%$, and $75 \%$ correspond to cut off points for low, moderate, and high degrees of heterogeneity. 


\section{Results}

The literature search produced 72 results. Figure 1 shows the PRISMA flow diagram detailing the process of study selection. Ultimately the process produced seven studies which were included in the final analysis ${ }^{1,15,68-72}$.

Table 1 describes the study designs and population characteristics of the seven included studies.

Methodological quality of the studies is summarised in Table 2. All studies adequately described the study setting and the predictor variables. All studies also produced tools which were clinically sensible and adequately reported their results. The areas which were most infrequently fulfilled were the blinding of those reporting the outcomes ( 0 of 7 ), blinding of those assessing the predictor variables (1 of 7), reproducibility of the predictor variables ( 1 of 7 ) and the application of the tool to all patients at risk ( 2 of 7 ).

Inclusion and exclusion criteria for each study are described in Table 1. A number of studies sought to exclude patients who were clearly more seriously injured. Some excluded patients who were haemodynamically unstable, others excluded patients with reduced Glascow Coma Scale (GCS). One paper excluded patients who presented in cardiac arrest or who arrested in the emergency department ${ }^{15}$. Two studies excluded patients when the GCS was 10 or below ${ }^{68-69}$. One study excluded patients with class III or IV shock or those requiring immediate surgery ${ }^{70}$. Two others excluded patients with systolic blood pressure (SBP) on admission of less than $90 \mathrm{mmHg}^{68,69}$.

The studies took different approaches to the use of CT scanning. Most studies included only patients who underwent a CT scan ${ }^{1,68,70,71}$. However, only one study adequately described their indications for performing a $\mathrm{CT}^{70}$. One study included only patients who underwent a 'definitive diagnostic test', however this could be CT, diagnostic peritoneal lavage (DPL) or surgical intervention (laparotomy or laparoscopy) ${ }^{15}$. Two studies included all patients, including those not undergoing a definitive investigation ${ }^{69,72}$. The majority of patients in these studies underwent DPL rather than $\mathrm{CT}$.

Most of the studies looked at a single $\mathrm{CPT}^{69-72}$. One study looked at a single CPT for the identification of IAI and a separate CPT for the need for acute surgical or radiological intervention ${ }^{15}$. One of the studies analysed the same data with four different CPTs ${ }^{1}$. Another analysed two separate CPTs ${ }^{68}$, using CPTs adapted from the studies by Mackersie ${ }^{72}$ and Grieshop ${ }^{69}$, included in this review. Therefore in total 11 CPTs are analysed.

The variables included in each study are described in Table 3 . The only variable included by all authors was chest injury, although the definition of this differed between studies. Only one author did not include an abnormal abdominal examination ${ }^{72}$. Similarly, one of the CPTs analysed by Garber et al ${ }^{68}$ (based on the 
CPT designed by Mackersie et $\mathrm{al}^{72}$ ) did not include an abnormal abdominal examination. Some authors specifically included only abdominal tenderness ${ }^{15,71}$.

All authors defined IAI as their primary outcome, with four papers including the need for intervention as a secondary outcome ${ }^{1,15,70,71}$. The definition of IAI varied between studies. Most studies included solid organ injuries (spleen, liver, kidney, pancreas, adrenal) and hollow viscus injuries (bowel, colon, bladder, ureter), vascular injuries to major intra-abdominal vessels, the presence of pneumoperitoneum and the presence of significant intra-abdominal free fluid ${ }^{1,15,69,71,72}$. One study also included fractures of the pelvis and lumber spine ${ }^{70}$. One study chose not to include bowel injuries ${ }^{68}$.

The need for acute intervention was generally defined as the requirement for operative or interventional radiological intervention ${ }^{1,15,71}$. One study additionally included the requirement for fracture fixation or stabilisation and the need for further diagnostic radiological investigations ${ }^{70}$.

Across all seven studies there was significant variation in the incidence of injury. The lowest incidence of IAI was $5.5 \%{ }^{71}$ and the highest $36.7 \%{ }^{68}$.

Four papers included evaluation of the predictor variables individually 1,15,69,72. Table 4 summarises the results for the seven variables analysed by more than one author. All seven are associated with significantly increased risk of IAI. A SBP of less than $90 \mathrm{mmHg}$ had the highest odds ratio followed by the presence of an associated chest injury and the presence of a lower haematocrit.

All studies described CPTs used for the assessment of risk of IAI. In total there were eleven CPTs analysed. Sensitivity, specificity, PPV and NPV for each of the CPTs are described in Table 5. The sensitivities ranged from $86 \%$ to $100 \%$. Specificity ranged from $11.8 \%$ to $100 \%$. The NPV ranged from $95.5 \%$ to $100 \%$. If these tools were applied to all patients then the frequency of which CT scans would have been ordered ranged from $26.5 \%$ to $89.7 \%$.

The three highest performing CPTs based on sensitivity were all from the same study, the highest having a sensitivity of $100 \%^{1}$. The next best performing study had a sensitivity of $97.4 \%{ }^{15}$.

If the lower limit of the $95 \%$ confidence interval $(\mathrm{Cl})$ is used, the poorest performing CPT had a lower limit of the $95 \% \mathrm{Cl}$ of just $59.7 \%^{71}$. The highest performing CPT had a lower limit of the $95 \% \mathrm{Cl}$ of $95.8 \%{ }^{15}$. Had this tool been applied to the population then $25.1 \%$ of patients would have avoided a CT scan.

Four studies described CPTs used for the assessment of the need for acute intervention ${ }^{1,15,70,71}$. In total there were seven CPTs analysed. Sensitivity, specificity, PPV and NPV for each of the CPTs are described in Table 6. The sensitivities ranged from $96 \%$ to $100 \%$. Five of the seven CPTs reached a sensitivity of $100 \% 1,15,71$. Specificity ranged from $11.0 \%$ to $34 \%$. The NPV ranged from $99.0 \%$ to $100 \%$. If these 
tools were applied to all patients then the frequency of which CT scans would have been ordered ranged from $67 \%$ to $90 \%$.

Once again, the highest performing CPT (using the lower limit of the $95 \% \mathrm{Cl}$ for sensitivity) was the study by Holmes et al ${ }^{15}$. The sensitivity of this study had a lower limit of the $95 \% \mathrm{Cl}$ of $97.2 \%$ and $26.0 \%$ of patients would have avoided a CT scan had this CPT been applied. 


\section{Discussion}

We have identified seven studies, producing eleven different CPTs. When the lower limit of the $95 \% \mathrm{Cl}$ for sensitivity is used the best performing CPT for the presence of IAI had a sensitivity of $97.4 \%(95 \% \mathrm{Cl}: 95.8-99.3 \%)$ and would have scanned $74.9 \%$ $(95 \% \mathrm{Cl}: 73.6-76.1 \%)$ of patients (Table 5$)^{15}$. This was also the study with the highest methodological quality score (11/14).

Four studies also used their CPTs to assess the requirement for acute intervention. Three of the CPTs produced by Poletti et al ${ }^{1}$ had sensitivities of $100 \%$, however the lower limit of their $95 \% \mathrm{Cl}$ was low between $83.4-84.0 \%$ (Table 6). Holmes et al ${ }^{15}$ also had a sensitivity of $100 \%$ ( $95 \% \mathrm{Cl}: 97.2-100 \%)$ but with a much more impressive lower confidence limit.

Neither of these CPTs include any measure of haemodynamic stability ${ }^{1,15}$. Therefore, in theory, a hypotensive patient may fail to trigger the tool. A potential reason for this may be that these patients are more likely to bypass the CT scanner and go straight to the operating room for definitive management and therefore would be less likely to be included in the study population. Clearly, it would be unacceptable for clinicians to not investigate such a patient.

To assess methodological quality we used a checklist involving the use of 14 factors considered to be important for the development of CPTs ${ }^{62-66}$. A number of quality issues were particularly poorly met; probably the most important of which was the failure to perform a CT scan for all patients at risk. Understandably, it is not necessarily desirable to scan every patient and authors overcame this problem in various ways. Some studies included all patients who presented with BAT but did not perform a CT scan on all included patients ${ }^{69,72}$. Others included only patients who underwent $\mathrm{CT}^{1,68,70,71}$.

Our systematic review demonstrates that even the poorest performing CPT achieved a sensitivity of $86.0 \%{ }^{72}$ with most studies achieving a sensitivity of comfortably over $90.0 \%$. Few of the studies included in this review analysed missed injuries but those that did, did not identify any injury missed by their CPT which required any intervention ${ }^{15,70,71}$. It would therefore appear possible to devise a CPT which, if used appropriately, will accurately identify higher risk patients in need of further investigation whilst missing very few injuries. The widespread use of similar CPTs for determining the need for imaging of the head and neck in trauma would suggest that this is a realistic aspiration ${ }^{56,57,73,74}$.

There is debate regarding the significance of missed injuries with no consistent definition in the literature of what constitutes a clinically important missed injury ${ }^{75}$. Some authors describe observation as a necessary intervention however it could be argued that observation of a trivial injury is unnecessary 37,75 . CPTs are unlikely to ever achieve $100 \%$ sensitivity for the identification of all injuries but the identification of the vast majority of injuries requiring intervention would appear achievable. It should also be noted that CT scanning itself does still miss injuries and 
that actually the better performing CPTs identified in this study have sensitivities very similar to those described for $\mathrm{CT}$ scanning ${ }^{10-14}$. A period of clinical observation will remain necessary for some patients (including some patients with a negative CT scan) and clinical decisions on imaging and discharge would be aided by more research focusing on criteria for the selective use of CT and clinical observation.

Performing routine WBCT is expensive and exposes large numbers of patients to potentially harmful doses of radiation. These risks are only justified if they are outweighed by the benefits and there is little evidence in the literature that this is the case for haemodynamically stable, fully conscious patients with no clinical signs or symptoms of injury. We have identified CPTs which have the potential to identify lower risk patients with a high degree of sensitivity and reduce significantly the number of patients requiring CT imaging. Whilst the majority of patients will still require $\mathrm{CT}$, this is probably justified for higher risk patients $33,35,36,40$. It is reasonable, however, to attempt to reduce the need for $\mathrm{CT}$ in lower risk patients and the use of well validated CPTs would seem an ideal way to achieve this.

Any study such as this has inevitable limitations. As is demonstrated in Table 2, the methodological quality of included studies is not high and the ability of any systematic review is limited by the quality of the included studies. The aim of this study was to attempt to review the evidence for CPTs which can determine whether a blunt trauma patient with few signs of serious injury requires an abdominal CT scan. In truth, few of the studies truly address this question as none robustly exclude patients with evidence of more severe injury. Such a study is problematic because any such study aiming to derive or validate a CPT, should include a gold standard reference against which the CPT should be assessed. Clearly a CT scan is the reference standard against which a CPT aimed at identifying IAI should be assessed. However, including only patients undergoing CT (as many studies included in this review have done) is likely to result in a group of patients with a higher risk of injury (as lower risk patients are less likely to be selected to undergo CT). The alternative approach, taken by some studies, is to include all patients but accept that not all will undergo a CT and rely instead on less accurate diagnostic tests or on clinical follow up only. This approach is then limited by the lack of a gold standard reference test.

In addition, all of the included studies are performed in the equivalent of Level 1 trauma centres and mostly in North America. This potentially limits the applicability of any conclusions to centres elsewhere, where the type of trauma experienced and the demographics of the population may differ, and to Emergency Departments which deal with a lower volume of trauma cases, where the staff may be less experienced. This emphasises the importance and need for studies to validate the results of potential CPTs in different populations.

Finally, the heterogeneity of the included studies makes direct comparison of them difficult. They differ in their patient selection, variables included in the CPTs, reference values and even in what is considered an intra-abdominal injury.

\section{Conclusions}


Although a number of the CPTs identified in this study appear to show promise, none have been validated in different environments or different populations and so it is impossible to recommend one particular CBT for routine clinical practice. Further studies should concentrate on attempting to validate existing CPTs in different populations. 


\section{References}

(1) Poletti PA, Mirvis SE, Shanmuganathan K, Takada T, Killeen KL, Perlmutter D, et al. Blunt abdominal trauma patients: can organ injury be excluded without performing computed tomography? J Trauma 2004;57(5):1072-1081.

(2) Livingston DH, Lavery RF, Passannante MR, Skurnick JH, Fabian TC, Fry DE, et al. Admission or observation is not necessary after a negative abdominal computed tomographic scan in patients with suspected blunt abdominal trauma: results of a prospective, multi-institutional trial. J Trauma 1998;44(2):273-80.

(3) Jones EL, Stovall RT, Jones TS, Bensard DD, Burlew CC, Johnson JL, et al. Intraabdominal injury following blunt trauma becomes clinically apparent within 9 hours. J Trauma Acute Care Surg 2014;76(4):1020-1023.

(4) Stanley AC, Vittemberger F, Napolitano LM, O'Hara KP, McGinnis K, Lockhart D, et al. The use of delayed computerized tomography in the evaluation of blunt abdominal trauma: a preliminary report. Am Surg 1999;65(4):369-374.

(5) Rodriguez A, DuPriest RW,Jr, Shatney $\mathrm{CH}$. Recognition of intra-abdominal injury in blunt trauma victims. A prospective study comparing physical examination with peritoneal lavage. Am Surg 1982;48(9):457-459.

(6) Schurink GW, Bode PJ, van Luijt PA, van Vugt AB. The value of physical examination in the diagnosis of patients with blunt abdominal trauma: a retrospective study. Injury 1997;28(4):261-265.

(7) Rothlin MA, Naf R, Amgwerd M, Candinas D, Frick T, Trentz O. Ultrasound in blunt abdominal and thoracic trauma. J Trauma 1993;34(4):488-495.

(8) Soyuncu S, Cete Y, Bozan H, Kartal M, Akyol AJ. Accuracy of physical and ultrasonographic examinations by emergency physicians for the early diagnosis of intraabdominal haemorrhage in blunt abdominal trauma. Injury 2007;38(5):564-569.

(9) WILSON CB, VIDRINE A,Jr, RIVES JD. Unrecognized Abdominal Trauma in Patients with Head Injuries. Ann Surg 1965;161:608-613.

(10) Nishijima DK, Simel DL, Wisner DH, Holmes JF. Does this adult patient have a blunt intra-abdominal injury? JAMA 2012;307(14):1517-1527.

(11) Peitzman AB, Makaroun MS, Slasky BS, Ritter P. Prospective study of computed tomography in initial management of blunt abdominal trauma. J Trauma 1986;26(7):585-592.

(12) Holmes JF, McGahan JP, Wisner DH. Rate of intra-abdominal injury after a normal abdominal computed tomographic scan in adults with blunt trauma. Am J Emerg Med 2012;30(4):574-579. 
(13) Fang JF, Wong YC, Lin BC, Hsu YP, Chen MF. Usefulness of multidetector computed tomography for the initial assessment of blunt abdominal trauma patients. World J Surg 2006;30(2):176-182.

(14) Salimi J, Bakhtavar K, Solimani M, Khashayar P, Meysamie AP, Zargar M. Diagnostic accuracy of CT scan in abdominal blunt trauma. Chin J Traumatol 2009;12(2):67-70.

(15) Holmes JF, Wisner DH, McGahan JP, Mower WR, Kuppermann N. Clinical prediction rules for identifying adults at very low risk for intra-abdominal injuries after blunt trauma. Ann Emerg Med 2009;54(4):575-584.

(16) Stephan PJ, McCarley MC, O'Keefe GE, Minei JP. 23-Hour observation solely for identification of missed injuries after trauma: is it justified? J Trauma 2002;53(5):895-900.

(17) Kendall JL, Kestler AM, Whitaker KT, Adkisson MM, Haukoos JS. Blunt abdominal trauma patients are at very low risk for intra-abdominal injury after emergency department observation. West J Emerg Med 2011;12(4):496-504.

(18) Lansink KW, Cornejo CJ, Boeije T, Kok MF, Jurkovich GJ, Ponsen KJ. Evaluation of the necessity of clinical observation of high-energy trauma patients without significant injury after standardized emergency room stabilization. J Trauma 2004;57(6):1256-1259.

(19) Cowell VL, Ciraulo D, Gabram S, Lawrence D, Cortes V, Edwards T, et al. Trauma 24-hour observation critical path. J Trauma 1998;45(1):147-150.

(20) Low R, Duber C, Schweden F, Lehmann L, Blum J, Thelen M. Whole body spiral $\mathrm{CT}$ in primary diagnosis of patients with multiple trauma in emergency situations. Rofo 1997;166(5):382-388.

(21) Leidner B, Beckman MO. Standardized whole-body computed tomography as a screening tool in blunt multitrauma patients. Emerg Radiol 2001;8:20-28.

(22) Philipp MO, Kubin K, Hormann M, Metz VM. Radiological emergency room management with emphasis on multidetector-row CT. Eur J Radiol 2003;48(1):2-4.

(23) Kanz KG, Paul AO, Lefering R, Kay MV, Kreimeier U, Linsenmaier U, et al. Trauma management incorporating focused assessment with computed tomography in trauma (FACTT) - potential effect on survival. J Trauma Manag Outcomes 2010;4:4.

(24) Rieger M, Czermak B, El Attal R, Sumann G, Jaschke W, Freund M. Initial clinical experience with a 64-MDCT whole-body scanner in an emergency department: better time management and diagnostic quality? J Trauma 2009;66(3):648-657. 
(25) Ahvenjarvi L, Mattila L, Ojala R, Tervonen O. Value of multidetector computed tomography in assessing blunt multitrauma patients. Acta Radiol 2005;46(2):177183.

(26) Smith CM, Woolrich-Burt L, Wellings R, Costa ML. Major trauma CT scanning: the experience of a regional trauma centre in the UK. Emerg Med J 2011;28(5):378382.

(27) Sampson MA, Colquhoun KB, Hennessy NL. Computed tomography whole body imaging in multi-trauma: 7 years experience. Clin Radiol 2006;61(4):365-369.

(28) Ruchholtz S, Waydhas C, Schroeder T, Piepenbrink K, Kuhl H, Nast-Kolb D. The value of computed tomography in the early treatment of seriously injured patients. Chirurg 2002;73(10):1005-1012.

(29) Wedegartner U, Lorenzen M, Nagel HD, Weber C, Adam G. Diagnostic imaging in polytrauma: comparison of radiation exposure from whole-body MSCT and conventional radiography with organ-specific CT. Rofo 2004;176(7):1039-1044.

(30) Weninger P, Mauritz W, Fridrich P, Spitaler R, Figl M, Kern B, et al. Emergency room management of patients with blunt major trauma: evaluation of the multislice computed tomography protocol exemplified by an urban trauma center. J Trauma 2007;62(3):584-591.

(31) Wurmb TE, Fruhwald P, Hopfner W, Keil T, Kredel M, Brederlau J, et al. Wholebody multislice computed tomography as the first line diagnostic tool in patients with multiple injuries: the focus on time. J Trauma 2009;66(3):658-665.

(32) Wurmb TE, Quaisser C, Balling H, Kredel M, Muellenbach R, Kenn W, et al. Whole-body multislice computed tomography (MSCT) improves trauma care in patients requiring surgery after multiple trauma. Emerg Med J 2011;28(4):300-304.

(33) Huber-Wagner S, Biberthaler P, Haberle S, Wierer M, Dobritz M, Rummeny E, et al. Whole-body CT in haemodynamically unstable severely injured patients--a retrospective, multicentre study. PLoS One 2013;8(7):e68880.

(34) Huber-Wagner S, Lefering R, Qvick LM, Korner M, Kay MV, Pfeifer KJ, et al. Effect of whole-body CT during trauma resuscitation on survival: a retrospective, multicentre study. Lancet 2009;373(9673):1455-1461.

(35) Hutter M, Woltmann A, Hierholzer C, Gartner C, Buhren V, Stengel D. Association between a single-pass whole-body computed tomography policy and survival after blunt major trauma: a retrospective cohort study. Scand J Trauma Resusc Emerg Med 2011;19:73.

(36) Kimura A, Tanaka N. Whole-body computed tomography is associated with decreased mortality in blunt trauma patients with moderate-to-severe 
consciousness disturbance: a multicenter, retrospective study. J Trauma Acute Care Surg 2013;75(2):202-206.

(37) Salim A, Sangthong B, Martin M, Brown C, Plurad D, Demetriades D. Whole body imaging in blunt multisystem trauma patients without obvious signs of injury: results of a prospective study. Arch Surg 2006;141(5):468-73.

(38) Gupta M, Schriger DL, Hiatt JR, Cryer HG, Tillou A, Hoffman JR, et al. Selective use of computed tomography compared with routine whole body imaging in patients with blunt trauma. Ann Emerg Med 2011;58(5):407-16.e15.

(39) Sierink JC, Saltzherr TP, Beenen LF, Russchen MJ, Luitse JS, Dijkgraaf MG, et al. A case-matched series of immediate total-body CT scanning versus the standard radiological work-up in trauma patients. World J Surg 2014;38(4):795-802.

(40) Yeguiayan JM, Yap A, Freysz M, Garrigue D, Jacquot C, Martin C, et al. Impact of whole-body computed tomography on mortality and surgical management of severe blunt trauma. Crit Care 2012;16(3):R101.

(41) Jiang L, Ma Y, Jiang S, Ye L, Zheng Z, Xu Y, et al. Comparison of whole-body computed tomography vs selective radiological imaging on outcomes in major trauma patients: a meta-analysis. Scand J Trauma Resusc Emerg Med 2014;22(1):54.

(42) Cardis E, Vrijheid M, Blettner M, Gilbert E, Hakama M, Hill C, et al. The 15Country Collaborative Study of Cancer Risk among Radiation Workers in the Nuclear Industry: estimates of radiation-related cancer risks. Radiat Res 2007;167(4):396416.

(43) Gilbert ES. Ionising radiation and cancer risks: what have we learned from epidemiology? Int J Radiat Biol 2009;85(6):467-482.

(44) Ashmore JP, Krewski D, Zielinski JM, Jiang H, Semenciw R, Band PR. First analysis of mortality and occupational radiation exposure based on the National Dose Registry of Canada. Am J Epidemiol 1998;148(6):564-574.

(45) Little MP. Cancer and non-cancer effects in Japanese atomic bomb survivors. J Radiol Prot 2009;29(2A):A43-59.

(46) Sont WN, Zielinski JM, Ashmore JP, Jiang H, Krewski D, Fair ME, et al. First analysis of cancer incidence and occupational radiation exposure based on the National Dose Registry of Canada. Am J Epidemiol 2001;153(4):309-318.

(47) Lin EC. Radiation risk from medical imaging. Mayo Clin Proc 2010;85(12):1142-6.

(48) Asha S, Curtis KA, Grant N, Taylor C, Lo S, Smart R, et al. Comparison of radiation exposure of trauma patients from diagnostic radiology procedures before and after the introduction of a panscan protocol. Emerg Med Australas 2012;24(1):43-51. 
(49) Brenner DJ, Elliston CD. Estimated radiation risks potentially associated with fullbody CT screening. Radiology 2004;232(3):735-738.

(50) Smith-Bindman R, Lipson J, Marcus R, Kim KP, Mahesh M, Gould R, et al. Radiation dose associated with common computed tomography examinations and the associated lifetime attributable risk of cancer. Arch Intern Med 2009;169(22):2078-2086.

(51) Miglioretti DL, Johnson E, Williams A, Greenlee RT, Weinmann S, Solberg LI, et al. The use of computed tomography in pediatrics and the associated radiation exposure and estimated cancer risk. JAMA Pediatr 2013;167(8):700-707.

(52) Journy N, Ancelet S, Rehel JL, Mezzarobba M, Aubert B, Laurier D, et al. Predicted cancer risks induced by computed tomography examinations during childhood, by a quantitative risk assessment approach. Radiat Environ Biophys 2014;53(1):39-54.

(53) Laack TA, Thompson KM, Kofler JM, Bellolio MF, Sawyer MD, Laack NN. Comparison of trauma mortality and estimated cancer mortality from computed tomography during initial evaluation of intermediate-risk trauma patients. J Trauma 2011;70(6):1362-1365.

(54) Adams ST, Leveson SH. Clinical prediction rules. BMJ 2012;344:d8312.

(55) Toll DB, Janssen KJ, Vergouwe Y, Moons KG. Validation, updating and impact of clinical prediction rules: a review. J Clin Epidemiol 2008;61(11):1085-1094.

(56) Stiell IG, Wells GA, Vandemheen K, Clement C, Lesiuk H, Laupacis A, et al. The Canadian CT Head Rule for patients with minor head injury. Lancet 2001;357(9266):1391-1396.

(57) Stiell IG, Wells GA, Vandemheen KL, Clement CM, Lesiuk H, De Maio VJ, et al. The Canadian C-spine rule for radiography in alert and stable trauma patients. JAMA 2001;286(15):1841-1848.

(58) Hoffman JR, Mower WR, Wolfson AB, Todd KH, Zucker MI. Validity of a set of clinical criteria to rule out injury to the cervical spine in patients with blunt trauma. National Emergency X-Radiography Utilization Study Group. N Engl J Med 2000;343(2):94-99.

(59) Haydel MJ, Preston CA, Mills TJ, Luber S, Blaudeau E, DeBlieux PM. Indications for computed tomography in patients with minor head injury. N Engl J Med 2000;343(2):100-105.

(60) Madden C, Witzkc DB, Arthur, Sanders B, Valente J, Fritz M. High-yield selection criteria for cranial computed tomography after acute trauma. Acad Emerg Med 1995;2(4):248-253. 
(61) Moher D, Liberati A, Tetzlaff J, Altman DG, PRISMA Group. Preferred reporting items for systematic reviews and meta-analyses: the PRISMA statement. Int J Surg 2010;8(5):336-341.

(62) Maguire JL, Boutis K, Uleryk EM, Laupacis A, Parkin PC. Should a head-injured child receive a head CT scan? A systematic review of clinical prediction rules. Pediatrics 2009;124(1):e145-54.

(63) McGinn TG, Guyatt GH, Wyer PC, Naylor CD, Stiell IG, Richardson WS. Users' guides to the medical literature: XXII: how to use articles about clinical decision rules. Evidence-Based Medicine Working Group. JAMA 2000;284(1):79-84.

(64) Laupacis A, Sekar N, Stiell IG. Clinical prediction rules. A review and suggested modifications of methodological standards. JAMA 1997;277(6):488-494.

(65) Wasson JH, Sox HC, Neff RK, Goldman L. Clinical prediction rules. Applications and methodological standards. N Engl J Med 1985;313(13):793-799.

(66) Stiell IG, Wells GA. Methodologic standards for the development of clinical decision rules in emergency medicine. Ann Emerg Med 1999;33(4):437-447.

(67) DerSimonian R, Laird N. Meta-analysis in clinical trials. Control Clin Trials 1986;7(3):177-188.

(68) Garber BG, Bigelow E, Yelle JD, Pagliarello G. Use of abdominal computed tomography in blunt trauma: do we scan too much? Can J Surg 2000;43(1):16-21.

(69) Grieshop NA, Jacobson LE, Gomez GA, Thompson CT, Solotkin KC. Selective use of computed tomography and diagnostic peritoneal lavage in blunt abdominal trauma. J Trauma 1995;38(5):727-731.

(70) Deunk J, Brink M, Dekker HM, Kool DR, Blickman JG, van Vugt AB, et al. Predictors for the selection of patients for abdominal CT after blunt trauma: a proposal for a diagnostic algorithm. Ann Surg 2010;251(3):512-520.

(71) Corwin MT, Sheen L, Kuramoto A, Lamba R, Parthasarathy S, Holmes JF. Utilization of a clinical prediction rule for abdominal-pelvic CT scans in patients with blunt abdominal trauma. Emerg Radiol 2014;21(6):571-576.

(72) Mackersie RC, Tiwary AD, Shackford SR, Hoyt DB. Intra-abdominal injury following blunt trauma. Identifying the high-risk patient using objective risk factors. Arch Surg 1989;124(7):809-813.

(73) National Institute for Clinical Excellence. Triage, assessment, investigation and early management of head injury in infants, children and adults. Clinical Guideline 56. 2007. 
(74) National Institute for Clinical Excellence. Head injury triage, assessment, investigation and early management of head injury in infants, children and adults. Clinical Guideline 4. 2003:96-97.

(75) Tillou A, Gupta M, Baraff LJ, Schriger DL, Hoffman JR, Hiatt JR, et al. Is the use of pan-computed tomography for blunt trauma justified? A prospective evaluation.

J Trauma 2009;67(4):779-87. 